\title{
EVIDENCIAÇÃO DOS CUSTOS E INVESTIMENTOS AMBIENTAIS DAS EMPRESAS DO SETOR DE QUÍMICOS DA B3 EVIDENTIATION OF COSTS AND ENVIRONMENTAL INVESTMENTS OF THE COMPANIES OF THE B3 CHEMICALS INDUSTRY
}

\author{
Maria Layane Silva Gomes ${ }^{1}$ \\ Lailson Silva Rebouças ${ }^{2}$ \\ Geison Calyo Varela de Melo $^{3}$ \\ Maria Naiula Monteiro da Silva ${ }^{4}$ \\ Sandra Maria dos Santos ${ }^{5}$
}

\section{RESUMO}

O objetivo do estudo foi investigar a evidenciação dos custos e investimentos ambientais das empresas pertencentes ao setor de químicos listadas na B3. A pesquisa caracteriza-se como descritiva e fez uso de métodos qualitativos. Para atingir o objetivo proposto foram coletados dados de 7 empresas pertencentes ao setor de químicos da B3 por meio das Demonstrações Financeiras Padronizadas, dos Balanços Sociais, dos Relatórios Anuais, dos Formulários 20F e dos Relatórios de Sustentabilidade dos exercícios de 2010 a 2016. Os resultados demonstraram que 70\% das empresas da amostra evidenciaram informações sobre custos e investimentos ambientais. As categorias de custos e investimentos mais evidenciadas foram custos com contingências e igualmente as categorias projetos ou programas ambientais e preservação e proteção ambiental. Também foi identificado que as empresas evidenciam essas informações predominantemente de forma quantitativa, mais especificamente na forma monetária. Pode-se concluir, ainda, que de um modo geral as empresas estão evidenciando poucas informações de cunho ambiental relacionados a custos e investimentos em meio ambiente, soma-se a isso a falta de padronização das informações encontradas, o que dificulta a comparabilidade dessas informações entre as empresas.

Palavras-chave: Evidenciação ambiental. Custos ambientais. Investimentos ambientais.

\footnotetext{
1 Mestranda em administração e controladoria. Universidade Federal do Ceará (UFC). E-mail: layane.silva97@gmail.com. 2 Mestrando em administração e controladoria. Universidade Federal do Ceará (UFC). E-mail:lailson15@hotmail.com

3 Mestrando em administração e controladoria. Universidade Federal do Ceará (UFC). E-mail: geisoncalyo@ hotmail.com

4 Doutora em Engenharia de Produção pela Universidade Federal de Santa Catarina. Professor Titular da Universidade Federal do Ceará. E-mail: naiula@ufc.br

5 Doutora em Economia pela Universidade Federal de Pernambuco. Professor Titular da Universidade Federal do Ceará. E-mail: smsantos@ufc.br
} 


\section{ABSTRACT}

The objective of this study was to investigate the disclosure of costs and environmental investments of companies belonging to the chemical sector listed in B3. The research is characterized as descriptive and made use of qualitative methods. To achieve the proposed objective, data were collected from 7 companies belonging to the chemical sector of B3 through Standardized Financial Statements, Social Balance Sheets, Annual Reports, Form 20F and Sustainability Reports for the years 2010 to 2016. The results showed that $70 \%$ of the companies in the sample showed information on environmental costs and investments. The categories of costs and investments most evidenced were costs with contingencies and also categories environmental projects or programs and environmental protection and preservation. It has also been identified that companies evidence this information predominantly quantitatively, more specifically in monetary form. It can also be concluded that, in general, companies are showing little environmental information related to costs and investments in the environment, in addition to the lack of standardization of the information found, which makes it difficult to compare this information between companies.

Keywords: Environmental evidence. Environmental costs. Environmental investments.

\section{INTRODUÇÃO}

Os problemas ambientais têm exigido uma nova postura por parte das empresas que utilizam recursos naturais e contribuem para a poluição do meio ambiente, no sentido de que adotem atitudes voltadas à preservação e recuperação ambiental (ROVER; BORBA; BORGERT, 2008).

Essa preocupação acerca dos problemas ambientais afetou o comportamento dos consumidores, fazendo com que prefiram consumir produtos que degradem menos o meio ambiente, obrigando as empresas a adotarem práticas sustentáveis no sentido de que se mantenham no mercado. Nesse contexto, não há como os gestores planejarem suas estratégias de mercado sem incluir a pauta ambiental (RODRIGUES; MACHADO; CRUZ, 2011; MORAES et al., 2017).

No Brasil, a alteração na Lei no 11.638/2007 não tornou obrigatória a divulgação de informações de caráter ambiental por parte de todas as empresas (MARQUEZAN et al., 2015). No entanto, houve um aumento da evidenciação de informações referente a custos ambientais nos últimos anos. Na visão de Nossa (2002), este fenômeno é decorrente da pressão social para que as empresas desempenhem suas atividades produtivas ao mesmo tempo em que contribuem para um desenvolvimento sustentável. Ao passo que a teoria da legitimidade tendo como pressuposto a manifestação das empresas em confirmar sua atuação diante da sociedade por meio do cumprimento aos princípios relativos ao meio ambiente, cidadania, costumes e o sistema jurídico no qual estão vinculados (CONCEIÇÃO et al., 2011).

As indústrias químicas, por ter alto potencial de impacto ambiental, foi um dos setores mais afetadas devido a esse aumento da preocupação ambiental (ASSOCIAÇÃO BRASILEIRA DA INDÚSTRIA QUÍMICA, 2015). Isso é decorrente, principalmente, da geração de resíduos proporcionada pela indústria química no seu processo produtivo, algo que sujeita as empresas desse setor a normas mais rigorosas, como a Lei n. 12.305, de 02 de agosto de 2010, que estabeleceu a Política Nacional de Resíduos Sólidos (PNRS) que visa, por exemplo, contribuir para a não geração, 
redução e tratamento de resíduos sólidos, aumentar a prática da reciclagem e promover inclusão social e geração de emprego e renda para catadores de materiais recicláveis (BRASIL, 2010).

Um importante meio de saber como as empresas estão lidando com a questão ambiental é através da evidenciação de informações desse gênero. Esse fato motivou a realização de pesquisas que analisaram a evidenciação de informações ambientais das empresas que compõem os vários setores da BM\&FBovespa, dentre eles: adubos e fertilizantes, papel e celulose, siderurgia e metalurgia e energia elétrica (RODRIGUES; MACHADO; CRUZ, 2011; MACEDO et al., 2007; PARENTE et $a l ., 2014)$. Além disso, estudos verificam que as legitimidades das empresas não estão relacionadas em ações e atitudes legítimas perante a sociedade e ao meio ambiente, mas apenas em garantir a continuidade das empresas (CORREA; GONÇALVES; MORAES, 2015).

Nesse contexto, entende-se ser importante analisar como as empresas do setor de químicos vêm evidenciando suas informações ambientais. Diante disso, esta pesquisa visa responder à seguinte questão: Qual o nível de evidenciação dos custos e investimentos ambientais das empresas listadas na B3 pertencentes ao setor de químicos?

O estudo tem como objetivo principal investigar a evidenciação dos custos e investimentos ambientais das empresas pertencentes ao setor de químicos listadas na B3. Os objetivos específicos, por sua vez, consistem em (a) categorizar as informações sobre custos e investimentos ambientais; (b) verificar em quais relatórios as informações sobre custos e investimentos ambientais foram evidenciadas; (c) identificar se as informações evidenciadas sobre custos e investimentos ambientais são do tipo monetária ou não monetária.

Para alcançar esses objetivos, o estudo, de natureza descritiva, com abordagem qualitativa e de caráter documental, utilizou a Análise de Conteúdo para analisar as informações contidas nas Demonstrações Financeiras Padronizadas (DFP), nos Relatórios Anuais (RA), nos Formulários 20F (20F), nos Balanços Sociais (BS) e nos Relatórios de Sustentabilidade (RS).

$\mathrm{O}$ estudo se justifica pela necessidade de evidenciação de informações ambientais por parte das empresas, tendo em vista que as ações ambientais e sociais das corporações refletem diretamente na sociedade, levando os agentes externos, segundo a Teoria da Legitimidade, a exigir cada vez mais a divulgação de informações ambientais. O setor de químicos, por exemplo, é um dos que mais contribuem para a geração de resíduos que podem vir a prejudicar o meio ambiente, algo que torna relevante socialmente estudar os aspectos da evidenciação de informações ambientais por parte dessas empresas. Ademais, o estudo contribui para a ampliação do conhecimento da área acadêmica sobre o tema de evidenciação de custos e investimentos ambientais voltado para o setor de químicos.

\section{REVISÃO BIBLIOGRÁFICA}

\subsection{CUSTOS E INVESTIMENTOS AMBIENTAIS}

Na contabilidade tradicional, o conceito de custo é definido, segundo Martins (2010), como todos os gastos de bens ou serviços empregados na produção de outros bens ou serviços. Do mesmo modo, os custos ambientais são todos os gastos que estão direta ou indiretamente relacionados com a neutralização e proteção do meio ambiente (RIBEIRO, 2010). 
Percebe-se que não há diferença conceitual entre custos e custos ambientais, da mesma forma que não há diferença entre despesa e despesa ambiental. Na contabilidade tradicional, despesa é todo ou bem ou serviço utilizado diretamente ou indiretamente com o intuito de obtenção de receita (MARTINS, 2010). Já as despesas ambientais são todos os gastos relacionados com o gerenciamento ambiental, utilizados no período e incorridos no setor administrativo (RIBEIRO, 2010). Fonseca et al. (2015) entendem ser importante conhecer esses conceitos para que não haja confusão quanto ao que é custo ambiental e despesa ambiental.

Hansen e Mowen (2003) classificaram os custos ambientais em: (a) custos de prevenção ambiental são aqueles derivados de atividades desenvolvidas pelas empresas com o objetivo de prevenir danos e desperdícios ao meio ambiente; (b) custos de detecção ambiental são os custos que visam identificar se as atividades da empresa estão atendendo as normas ambientais de forma adequada; (c) custos de falhas ambientais internas são os custos incorridos para eliminar, conter ou gerir a contaminação e desperdício antes que sejam despejados no meio ambiente; (d) custos de falhas ambientais externas são os custos incorridos e pagos pela empresa referente a atividades pós processo produtivo, ou seja, depois que contaminantes e desperdício são despejados no meio ambiente; e (e) custos não realizados de falhas externas (custos sociais) que correspondem aos custos de atividades após o descarregamento de contaminantes e desperdício no meio ambiente, nesse caso são atividades desenvolvidas por pessoas não externas à empresa.

Tinoco e Kraemer (2011) também definiram os custos ambientais em: (a) custos potencialmente ocultos que referem-se aos custos de conformidade, ou seja, são os custos incorridos para que a empresa atue conforme as leis e outras políticas ambientais relacionadas a sua atividade; (b) custos convencionais são todos os custos dos processos e atividades da empresa relacionados a quaisquer aspectos ambientais e tangíveis; (c) custos com contingências são gastos que podem vir a incorrer ou não dependendo de futuros custos de regulamentação, multas e penalidades; e (d) custos de imagem e relacionamento são os custos relacionadas a visão e o relacionamento desenvolvido entre os stakeholders e a empresa.

No que diz respeito aos investimentos, estes são definidos, de acordo com Vellani e Nakao (2009, p. 160), como "todos os gastos incorridos, e a incorrer, para aquisição de ativos que tenham relação com os processos de preservação, controle e recuperação do meio ambiente visando benefícios futuros".

Rover, Borba e Borgert (2008) classificaram os investimentos ambientais nas seguintes categorias: (a) investimentos com educação ambiental; (b) investimentos para manutenção dos processos operacionais e melhoria do meio ambiente; (c) investimentos com projetos ou programas ambientais; (d) investimentos para recuperação de danos ambientais; e (e) investimentos para preservação e proteção ambiental.

Quanto à caracterização das informações ambientais evidenciadas pelas empresas, Rover, Borba e Borgert (2008), utilizaram quatro tipos de evidenciação mutuamente excludentes e exaustivas para identificar como as informações divulgadas pelas empresas foram apresentadas nos relatórios: (a) declarativa é quando as informações são apresentadas de forma descritiva; (b) quantitativa nãomonetária são as informações quantitativas evidenciadas através de números não-financeiras; (c) quantitativa monetária são as informações quantitativas evidenciadas de forma financeira e; (d) 
quantitativa monetária e não-monetária refere-se a informações evidenciadas tanto de forma financeira quanto não-financeira.

Ainda em relação aos custos ambientais e de acordo com Fonseca et al. (2015), buscouse analisar a evolução da classificação e evidenciação de informações relacionadas aos custos ambientais das empresas do setor de papel e celulose pertencentes a BM\&FBovespa e dessa forma, foi constatada uma evolução da evidenciação de informações ambientais tanto de forma qualitativa quanto quantitativa em relação a estudos anteriores.

Já em relação aos investimentos ambientais, Silva et al. (2017) analisaram os investimentos de caráter socioambiental das 16 empresas que participaram de todas as edições do ISE e chegaram à conclusão de que os setores que evidenciaram menos investimentos socioambientais, buscaram compensar esse déficit apresentando um- maior nível de disclosure socioambiental, além disso, essas empresas, com o intuito de se legitimar perante a sociedade, evidenciam predominantemente informações de investimentos e disclosure sociais.

\subsection{LEGITIMAÇÃO DAS ORGANIZAÇÕES}

De acordo com Patten e Cho (2007), a Teoria da Legitimidade transmite a ideia de que a evidenciação de informações socioambientais é motivada pela pressão exercida pela opinião pública no ambiente social e político no qual a empresa está inserida. Desse modo, empresas que possuem um grau de exposição maior ao julgamento da sociedade, por exemplo, aquelas que apresentam pior desempenho ambiental, tem tendência a fornecer informações ambientais positivas, de forma a manter a sua legitimidade.

Suchman (1995) apresenta três formas através das quais as empresas podem buscar legitimar suas operações. A primeira é a pragmática que corresponde a uma forma prática e imediata da empresa em responder os anseios do seu público; a segunda é a moral, que diz respeito a avaliação normativa positiva da entidade e de suas atividades, e no julgamento das atividades feitas pela empresa; a terceira é a cognitiva e está relacionada a importância e essencialidade da empresa no contexto social em que está inserida.

Esse mesmo autor destaca a importância da evidenciação de informações ambientais como instrumento de legitimação social para as empresas, algo que vem sendo amplamente utilizado tanto no processo de transparência da gestão econômico-financeira, quanto na gestão socioambiental das entidades, principalmente para atender as demandas do mercado altamente competitivo em que exercem suas atividades, objetivando garantir sua sustentabilidade (SUCHMAN, 1995).

Adicionalmente, Deegan (2002) aponta uma variedade de fatores que podem exercer influência na decisão dos gestores em evidenciar voluntariamente informações socioambientais. Esses fatores incluem: atender os requisitos legais; preocupação com questões econômicas; accountability; obtenção de empréstimos; atender às pressões sociais; manter a legitimidade da empresa; atrair investimentos.

Desse modo, percebe-se que as empresas têm demonstrando uma adequação em relação ao campo ambiental visando sua legitimação, e que a divulgação de caráter ambiental é relevante para legitimar suas ações diante da sociedade a qual a administração pode influenciar as percepções externas (SUCHMAN, 1995; DEEGAN, 2002). 


\subsection{DIVULGAÇÃO DE INFORMAÇÕES AMBIENTAIS}

O disclosure ambiental segundo Correa, Gonçalves e Moraes (2015), está relacionado a evidenciação de informações socioambientais. A evidenciação destas informações pode ocorrer de forma compulsória ou voluntária. Quando a evidenciação é determinada por lei tem-se o tipo compulsório, quando a evidenciação é feita por opção da própria empresa tem-se a voluntária (RAFAELLI et al., 2014).

Com exceção de alguns setores regulados, grande parte das empresas brasileiras não é obrigada a divulgar informações ambientais (ALMEIDA-SANTOS et al., 2012), mas são feitas recomendações por algumas entidades, por exemplo, a Comissão de Valores Mobiliários (CVM) e o Conselho Federal de Contabilidade (CFC) através do Parecer de Orientação no 15/87 e da Resolução no 1.003/04, respectivamente (CORREA; GONÇALVES; MORAES, 2015).

A divulgação ambiental, portanto, diz respeito a informações de caráter ambiental, divulgadas de forma obrigatória ou voluntária pelas empresas através de seus relatórios, com o objetivo de satisfazer a necessidade de um usuário, ou até mesmo melhorar a sua reputação corporativa (ALMEIDA-SANTOS et al., 2012)

Marquezan et al. (2015) destaca que o Balanço Social do Instituto Brasileiro de Análises Sociais e Econômicas no Brasil (IBASE), o Form-20 e o Global Reporting Initiave (GRI) são iniciativas adotadas de forma voluntária no Brasil para a divulgação de informações ambientais.

Desse modo, a teoria da legitimidade tem sido utilizada em vários estudos para obter uma melhor percepção das práticas de divulgação ambiental (COMIER; MAGNAN, 2013). De tal modo, as elaborações de relatórios sociais e ambientais como uma ferramenta estratégica (SPENCE, HUSILLOS; CORREA-RUIZ, 2010), mas também como um meio de garantir a continuidade das empresas (DEEGAN, 2002; CORREA; GONÇALVES; MORAES, 2015). Ressalta-se que a pesquisa dá ênfase a Teoria da Legitimidade, de acordo com Eugenio (2010), é a teoria que aborda com mais compreensão a divulgação ambiental.

\section{METODOLOGIA}

Cervo, Bervian e Silva (2010, p. 61) afirmam que a pesquisa descritiva "observa, registra, analisa e correlaciona fatos ou fenômenos (variáveis) sem manipulá-los. Procura descobrir com a maior precisão possível, a frequência com que um fenômeno ocorre, sua relação e conexão com outros, sua natureza e características". A presente pesquisa classifica-se, portanto, quanto aos objetivos, como descritiva, uma vez que irá expor as características de um determinado grupo (GIL, 2008).

Quantos aos procedimentos, o estudo classifica-se como bibliográfico e documental. Enquadrase como uma pesquisa bibliográfica, pois utiliza obras de outros autores que já trataram sobre o tema que será estudado, e documental, pois analisa documentos que ainda não passaram por nenhum tratamento analítico (GIL, 2008).

Já a abordagem da pesquisa utilizou métodos qualitativos. De acordo com Martins e Theóphilo (2007, p. 135) esta abordagem permite que o fenômeno em estudo seja analisado de uma forma mais específica, sendo necessário "descrições, compreensões, interpretações e análises de informações, fatos, ocorrências, evidências que naturalmente não são expressas por números". 
A população da pesquisa consiste nas 7 empresas do setor de químicos listadas na B3 de 2010 a 2016 (Quadro 2). No entanto, a amostra final da pesquisa foi constituída por 5 companhias, uma vez que as empresas Nutriplant Indústria e Comércio S.A. e GPC Participações S.A. não evidenciaram informações sobre custos e investimentos ambientais nos exercícios estudados. Destaca-se ainda, que a escolha da amostra resultou do alto impacto ambiental desse setor. Segundo a Lei n. 10.165 de 2000, em seu Anexo VIII, as empresas do setor de químicos são consideradas potencialmente poluidoras (BRASIL, 2000). Já a escolha do período foi motivada pela busca de dados mais recentes.

Quadro 2 - Empresas pertencentes ao setor de químicos listadas na B3.

\begin{tabular}{|l|l|l|c|}
\hline Razão social & Segmento & Razão social & Segmento \\
\hline Fertilizantes Heringer S.A. & NM & GPC Participações S.A. & - \\
\hline $\begin{array}{l}\text { Nutriplant Indústria e } \\
\text { Comércio S.A. }\end{array}$ & MA & Cristal Pigmentos do Brasil S.A. & - \\
\hline Braskem S.A. & N1 & Unipar Carbocloro S.A. & - \\
\hline Elekeiroz S.A. & & & - \\
\hline
\end{tabular}

Fonte: Dados da pesquisa (2018).

Legenda: Novo Mercado (NM), Bovespa Mais (MA) e Nível 1 de Governança Corporativa (N1).

Para alcançar os objetivos propostos por esse estudo, foi utilizado o mesmo método proposto por Hansen e Mowen (2003), Rover, Borba e Borgert (2008) e Tinoco e Kraemer (2011), que consistiu em uma análise de dados secundários composta pelas: Demonstrações Financeiras Padronizadas (DFP), os Relatórios Anuais (RA), os Formulários 20F (F20F), os Balanços Sociais (BS) e os Relatórios de Sustentabilidade (RS). As informações que constituem as DFP, são: Balanço Patrimonial; Demonstração do Resultado do Exercício; Demonstração das Mutações do Patrimônio Líquido; Relatório da Administração; Notas Explicativas e Parecer dos Auditores Independentes.

Os documentos citados foram obtidos por meio de consulta eletrônica aos websites das empresas que fazem parte da amostra. O tempo em que esses relatórios foram analisados compreendem o período de 2010 a 2016. Destaca-se que no website da empresa Cristal Pigmentos do Brasil S.A. foram encontrados documentos referentes apenas ao período de 2013 a 2016.

Apartir dos dados obtidos por meio das DFP, dos RA, dos RS, dos BS e dos F20F disponibilizados nos sites das empresas foi aplicada a técnica de análise de conteúdo. O procedimento adotado para realizar a análise de conteúdo foi a categorização. Esta técnica, de acordo com Bardin (1977), é útil para categorizar os dados obtidos em uma pesquisa.

As categorias utilizadas para classificar os dados encontrados foram custos e investimentos ambientais que correspondem ao tema abordado na pesquisa. Este critério é classificado, ainda segundo Bardin (1997), como semântico. Neste sentido, esta técnica visa identificar e classificar os dados referentes aos custos e investimentos ambientais das empresas estudadas. 
Para a coleta destes dados foram pesquisadas as palavras-chave "custo", "investimento", "ambiente" e "ambiental". Em seguida foi feita a leitura das informações correspondentes às palavraschave de modo a identificar se as informações encontradas correspondiam a custos e investimentos ambientais.

As classificações utilizadas para as sentenças de custos e investimentos ambientais evidenciados pelas empresas basearam-se em estudos anteriores realizados por (HANSEN; MOWEN, 2003; ROVER; BORBA; ORGERT,2008; TINOCO; KRAEMER, 2011).

\section{ANÁLISE DOS RESULTADOS}

\subsection{EVIDENCIAÇÃO DE CUSTOS E INVESTIMENTOS AMBIENTAIS}

Os relatórios analisados permitiram fazer uma identificação das informações sobre custos e investimentos ambientais em 5 das 7 empresas pesquisadas, de modo que as empresas Nutriplant Indústria e Comércio S.A. e GPC Participações S.A. foram as únicas que não evidenciaram informações sobre custos e investimentos ambientais no período analisado.

\subsubsection{Fertilizantes Heringer S.A.}

Os Quadros 2 e 3 apresentam as informações de custos e investimentos ambientais evidenciadas nas Demonstrações Financeiras Padronizadas (DFP) e no Relatório de Sustentabilidade (RS) da empresa Fertilizantes Heringer S.A.

Quadro 2 - Evidenciação de custos ambientais na empresa Fertilizantes Heringer S.A.

\begin{tabular}{|c|c|l|}
\hline Exercício & Relatório & \multicolumn{1}{|c|}{ Descrição da informação } \\
\hline 2010 & $\begin{array}{c}\text { DFP } \\
\text { RS }\end{array}$ & Não houve evidenciação. \\
\hline 2011 & DFP & $\begin{array}{l}\text { Incentivo aos clientes para procederem à análise de solo das suas propriedades, patrocinando } \\
50 \% \text { do custo desse serviço. Em 2011, foram feitas mais de 50.000 análises de solo. }\end{array}$ \\
\hline 2012 & DFP & $\begin{array}{l}\text { Ações de natureza cível e ambiental no valor de R\$ 63.788. } \\
\text { Duas multas de R\$ 2.766,00 cada por operar fonte de poluição sem possuir a licença de operação } \\
\text { renovada pela Companhia Ambiental do Estado de São Paulo (Cetesb) nas Unidade I e II: } \\
\text { Paulínia. }\end{array}$ \\
\hline 2012 & RS & Não houve evidenciação. \\
\hline 2013 & DFP & Ações de natureza cível e ambiental no valor de R\$ 22. 734. \\
\hline 2013 & RS & $\begin{array}{l}\text { Fomento aos clientes para a análise do solo subsidiando parte dos custos com o intuito de } \\
\text { mitigar os impactos ambientais locais. }\end{array}$ \\
\hline 2014 & DFP & Não houve evidenciação. \\
\hline 2015 & DFP & Não houve evidenciação. \\
\hline 2015 & RS & $\begin{array}{l}\text { Fomento aos clientes para a análise do solo subsidiando parte dos custos com o intuito de } \\
\text { mitigar os impactos ambientais locais. }\end{array}$ \\
\hline 2016 & DFP & Não houve evidenciação. \\
\hline 2016 & RS & $\begin{array}{l}\text { Fomento aos clientes para a análise do solo subsidiando parte dos custos com o intuito de } \\
\text { mitigar os impactos ambientais locais. }\end{array}$ \\
\hline
\end{tabular}

Fonte: Dados da pesquisa (2018). 
É possível inferir, a partir dos dados encontrados, que foram evidenciadas poucas informações relacionadas a custos ambientais. A informação de que a empresa auxilia financeiramente seus clientes a analisar o solo onde estes plantam, é classificada, de acordo com Hansen e Mowen (2003), como custo de prevenção ambiental. Já a informação de que a empresa estava envolvida em ação cível e ambiental é classificado por Tinoco e Kraemer (2011) como custos com contingências. As informações evidenciadas pela empresa enquadram-se, segundo Rover, Borba e Borgert (2008) como declarativa, quantitativa monetária e quantitativa não-monetária.

O Quadro 3 apresenta informações referente aos investimentos ambientais da empresa Fertilizantes Heringer S.A.

Quadro 3 - Evidenciação de investimentos ambientais na empresa Fertilizantes Heringer S.A.

\begin{tabular}{|c|c|c|}
\hline Exercício & Relatório & Descricão da informacão \\
\hline 2010 & DFP & $\begin{array}{l}\text { Investimentos em medidas ambientais preventivas e antecipatórias, além de possuir um sistema } \\
\text { de gestão ambiental que permite desenvolver e implementar políticas e objetivos que levam em } \\
\text { consideração requisitos legais e informações sobre aspectos ambientais significativos. }\end{array}$ \\
\hline 2011 & DFP & $\begin{array}{l}\text { Investimentos em medidas ambientais preventivas e antecipatórias, além de possuir um sistema } \\
\text { de gestão ambiental que permite desenvolver e implementar políticas e objetivos que levam em } \\
\text { consideração requisitos legais e informações sobre aspectos ambientais significativos. }\end{array}$ \\
\hline 2011 & $\mathrm{RS}$ & $\begin{array}{l}\text { Investimentos em melhorias de controles ambientais e programas de prevenção e mitigação de } \\
\text { riscos e impactos ao meio ambiente. } \\
\text { Investimento de } \mathrm{R} \$ 6.222 .402,06 \text { em Proteção Ambiental. } \\
\text { Implantação de projeto para reutilização de } 100 \% \text { de todo o efluente líquido gerado na planta em } \\
\text { sistema de circuito fechado. Além de reutilização de água de chuvas. } \\
\text { Contribuição para o programa de arborização na cidade de Ourinhos-SP, por meio do plantio de } \\
2.500 \text { árvores nativas. } \\
\text { Plantio de } 787 \text { mudas nativas em Paulínia-SP. }\end{array}$ \\
\hline 2012 & DFP & $\begin{array}{l}\text { nvestimentos em medidas ambientais preventivas e antecipatórias, além de possuir um sistema } \\
\text { de gestão ambiental que permite desenvolver e implementar políticas e objetivos que levam em } \\
\text { consideracão requisitos legais e informacoões sobre aspectos ambientais significativos. }\end{array}$ \\
\hline 2012 & $\mathrm{RS}$ & $\begin{array}{l}\text { Investimentos em melhorias de controles ambientais e programas de prevenção e mitigação de } \\
\text { riscos e impactos ao meio ambiente. } \\
\text { Investimento de R } \$ 6.530 .244,45 \text { em Proteção Ambiental. } \\
\text { Utilização de biodiesel nos caminhões da frota própria, compra de automóveis flex para a frota, } \\
\text { realização de queima de biomassa para a geração de vapor (na produção da linha especial de } \\
\text { fertilizantes "Nitrogold", na unidade de Rosário do Catete- SE), substituição dos motores } \\
\text { elétricos por motores de alta performance de rendimento e utilização de fotocélulas nos refletores } \\
\text { instalados nos ambientes externos. } \\
\text { Início do Projeto Verde que consiste no plantio de } 4 \text { mil mudas de essências nativas dentro da } \\
\text { área judustrial, para fortalecer a faixa de floresta nativa existente na área. }\end{array}$ \\
\hline 2013 & DEP & $\begin{array}{l}\text { Não houve evidenciacão. } \\
\text { Investimento de R\$ } 6.940 .539 \text { em Proteção Ambiental. }\end{array}$ \\
\hline 2013 & RS & $\begin{array}{l}\text { Implantação do Projeto Verde na unidade de Dourados (MS), onde foram plantadas } 2.700 \text { mudas } \\
\text { de árvores nativas. Utilização do bagaço de cana como fonte de energia renovável na produção } \\
\text { da linha de nitrogold. na unidade de Rosário do Catete (SE). }\end{array}$ \\
\hline 2014 & DFP & Não houve evidenciaçẫo. \\
\hline 2014 & RS & $\begin{array}{l}\text { Apoio ao projeto Viveiro de Mudas Nativas do Bioma Cerrado por meio da doação de fertilizantes } \\
\text { e de assistência técnica. O projeto consiste na produção de } 5 \text { mil mudas de espécies nativas do } \\
\text { bioma Cerrado. } \\
\text { Copatrocínio da XIV Semana do Meio Ambiente e XVII Eco Dourados, cujo tema foi "Sociedade } \\
\text { em desenvolvimento: reconstruindo práticas e conceitos". } \\
\text { Início da construção de duas novas unidades misturadoras, nos municípios de Candeias (BA) e Rio } \\
\text { Grande (RS), nas quais o cuidado com o meio ambiente e o compromisso com a sustentabilidade } \\
\text { estiveram presentes desde o começo das obras. } \\
\text { Patrocínio do Projeto Trilha Ecológica Sentinela do Caparaó, promovido pela Patrulha de } \\
\text { Prevenção à Degradação Ambiental (PPMAMB), que busca promover a educação ambiental da } \\
\text { comunidade de Manhuaçu (MG). } \\
\text { Reciclagem de } 51 \text { toneladas de materiais utilizados na produção. }\end{array}$ \\
\hline 2015 & DFP & \\
\hline
\end{tabular}




\begin{tabular}{|c|c|l|}
\hline 2015 & RS & $\begin{array}{l}\text { Patrocínio do Projeto Mar cuja proposta é sensibilizar a sociedade sobre a importância e a } \\
\text { necessidade de preservar o mar. } \\
\text { Colaboração no Projeto Cereais (Centro de Reintrodução de Animais Selvagens) por meio de } \\
\text { recursos financeiros. A iniciativa visa tratar e devolver à natureza aves, mamíferos e répteis } \\
\text { saudáveis, contribuindo para a preservação do meio ambiente. }\end{array}$ \\
\hline 2016 & DEP & $\begin{array}{l}\text { Nãohouve evidenciacão. } \\
\text { Aportes em controles relativos a meio ambiente em 100\% das unidades da Heringer. } \\
\text { Colaboração no Projeto Cereais (Centro de Reintrodução de Animais Selvagens) por meio } \\
\text { de recursos financeiros, cujo objetivo é tratar e devolver à natureza aves, mamíferos e répteis } \\
\text { saudáveis, contribuindo para a preservação do meio ambiente. }\end{array}$ \\
\hline
\end{tabular}

Fonte: Dados da pesquisa (2018).

De acordo com a categorização identificada por Rover, Borba e Borgert (2008) é possível observar que as informações sobre investimentos ambientais evidenciadas pela empresa consistem em: investimentos para manutenção dos processos operacionais e melhoria do meio ambiente, investimentos em projetos ou programas ambientais e investimentos para preservação e proteção ambiental. Ainda segundo Rover, Borba e Borgert (2008) essas informações são do tipo declarativa, quantitativa monetária e quantitativa não monetária.

\subsubsection{Braskem S.A.}

No Quadro 4 são apresentadas as informações evidenciadas pela Brasken S.A. referente aos seus custos ambientais. No período estudado foram coletados dados do Formulário 20F (F20F), do Relatório Anual (RA) e do Relatório de Sustentabilidade (RS).

Quadro 4 - Evidenciação de custos ambientais na empresa Braskem S.A.

\begin{tabular}{|c|c|c|}
\hline Exercício & Relatório & Descrição da informação \\
\hline 2010 & F20F & $\begin{array}{l}\text { Início da produção de uma planta de polietileno fabricado totalmente a partir de recursos } \\
\text { renováveis. O custo total do projeto foi de } \mathrm{R} \$ 488 \text { milhões. } \\
\text { Provisão para contingências ambientais no valor de } \mathrm{R} \$ 36,3 \text { milhões. } \\
\text { Despesas anuais com atendimento ao controle ambiental no valor de } \mathrm{R} \$ 134,9 \text { milhões. }\end{array}$ \\
\hline 2010 & $\begin{array}{l}\text { RA } \\
\text { RS }\end{array}$ & 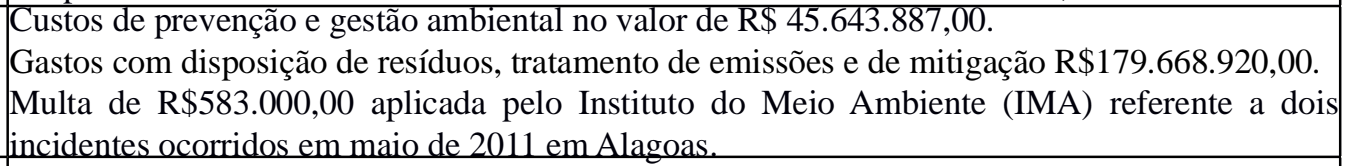 \\
\hline 2011 & F20F & Provisão para contingências ambientais no valor de $\mathrm{R} \$ 36,8$ milhões. \\
\hline 2011 & RA & Despesas anuais com atendimento ao controle am \\
\hline 2012 & $\mathrm{~F} 20 \mathrm{~F}$ & $\begin{array}{l}\text { Despesas anuais com atendimento ao controle ambiental no valor de } \mathrm{R} \$ 256,3 \text { milhões. } \\
\text { Provisão para contingências ambientais no valor de } \mathrm{R} \$ 32,9 \text { milhões. }\end{array}$ \\
\hline 2013 & F20F & $\begin{array}{l}\text { Despesas anuais com atendimento ao controle ambiental no valor de } \mathrm{R} \$ 292,6 \text { milhões. } \\
\text { Provisão para contingências ambientais no valor de } \mathrm{R} \$ 59,4 \text { milhões. }\end{array}$ \\
\hline 2014 & $\mathrm{~F} 20 \mathrm{~F}$ & $\begin{array}{l}\text { Despesas anuais com atendimento ao controle ambiental no valor de } \mathrm{R} \$ 190,00 \text { milhões. } \\
\text { Provisão para contingências ambientais no valor de } \mathrm{R} \$ 26.2 \text { milhões. }\end{array}$ \\
\hline 2014 & RA & $\begin{array}{l}\text { R } \$ 385,8 \text { milhôes referente a projetos de melhorias de process } \\
\text { bientais e de eficiência energética. }\end{array}$ \\
\hline 2015 & F20F & $\begin{array}{l}\text { Despesâs anuais com atendimento ao controle ambiental no valor de R\$221,9 milhões. } \\
\text { Provisão para contingências ambientais no valor de } R \$ 127,2 \text { milhões }\end{array}$ \\
\hline 2016 & $\mathrm{~F} 20 \mathrm{~F}$ & $\begin{array}{l}\text { Despesas anuais com atendimento ao controle ambiental no valor de } \mathrm{R} \$ 325,3 \text { milhões. } \\
\text { Provisão para contingências ambientais no valor de } \mathrm{R} \$ 254,00 \text { milhões. }\end{array}$ \\
\hline 2016 & RA & Custos evitados em gestão de saúde, segurança e meio ambiente: $\mathrm{R} \$ 252,4$ milhões. \\
\hline
\end{tabular}

Fonte: Dados da pesquisa (2018). 
Ao analisar as sentenças apresentadas no Quadro 4 é possível identificar que todas as informações evidenciadas são quantitativas, e classificam-se como quantitativas monetárias, segundo Rover, Borba e Borgert (2008). Além disso, são categorizadas, de acordo Hansen e Mowen (2003) como custos de detecção ambiental, uma vez que as despesas incorridas estão relacionadas ao controle ambiental e as provisões às contingências ambientais. Destaca-se também a informação referente a multa aplicada a empresa no valor de $\mathrm{R} \$ 583.000,00$, classificada por Tinoco e Kraemer (2011) como custos com contingência.

O Quadro 5 apresenta as informações referentes aos investimentos ambientais evidenciadas pela empresa Brasken S.A. nos Formulário 20F (F20F), no Relatório Anual (RA), no Relatório de Sustentabilidade (RS) e nas Demonstrações Financeiras Padronizadas (DFP) nos exercícios de 2010 a 2016.

Quadro 5- Evidenciação de investimentos ambientais na empresa Braskem S.A.

\begin{tabular}{|c|c|c|}
\hline Exercício & elatório & Descrição da infọmação \\
\hline 2010 & & Investimentos de R $\$ 343,1$ milhões na construção de instalações de polietileno "verde". \\
\hline 2010 & $\begin{array}{l}\text { RA } \\
\text { RS }\end{array}$ & $\begin{array}{l}\text { Inauguração da planta de eteno derivado do etanol que dẽmandou investimentos de } \\
\text { aproximadamente R\$ } 500 \text { milhões, cuja produção é de } 200 \text { mil toneladas anuais de polietileno } \\
\text { (PE) verde. } \\
\text { Investimentos em projeto socioambientais no valor de R } \$ 16,3 \text { milhões. } \\
\text { Construção de uma planta de propeno (PP) verde, com investimentos de US\$ } 100 \text { milhões } \\
\text { (projeto ainda em estágio inicial). } \\
\text { Investimento de R } \$ 16,4 \text { milhões na comunidade, incluindo compensações ambientais acordadas } \\
\text { com órgãos financiadores. } \\
\text { Investimento de R } \$ 103 \text { milhões em saúde, segurança e meio ambiente (SSMA). } \\
\text { Investimento de R } \$ 7,1 \text { milhões em projetos socioambientais associados a novos investimentos. } \\
\text { Investimento em projeto único de reciclagem para municípios de algumas regiões de São Paulo, } \\
\text { Rio de Janeiro, Rio Grande do Sul, Alagoas e Bahia. } \\
\text { Investimentos em gastos e proteção ambiental no valor de R } \$ 6.137 .717,00 \text {. } \\
\text { Investimentos de R } \$ 3,5 \text { milhões no programa Qualidade e Consumo Responsável de Sacolas } \\
\text { Plásticas. } \\
\text { Destinou R } \$ 4,6 \text { milhões ao Programa de Desenvolvimento Integrado e Sustentável do Mosaico } \\
\text { de APAs do Baixo Sul da Bahia - PDIS. }\end{array}$ \\
\hline 2010 & DFP & $\begin{array}{l}\text { Investimentos de R } \$ 103 \text { míthões em SSMA. } \\
\text { Investimento no desenvolvimento de um projeto único de reciclagem para as regiões de São } \\
\text { Paulo, Alagoas e Bahia. } \\
\text { Desenvolvimento de Produtos Verdes, produzidos a partir de matéria-prima renovável, } \\
\text { contribuindo para a redução da emissão de } 500 \text { mil toneladas de } \mathrm{CO} 2 \text { por ano. } \\
\text { Investimento em projetos de Responsabilidade Social: Programa de Educação Ambiental Lagoa } \\
\text { Viva; Cinturão Verde; Projetos de Reciclagem; Recicla Sul; Fábrica de Florestas; e Parque da } \\
\text { Amizade. }\end{array}$ \\
\hline 2011 & $\mathrm{~F} 20 \mathrm{~F}$ & $\begin{array}{l}\text { Investimento em novos negócios, entre eles, o processo para produzir polipropileno "verde", em } \\
\text { parceria com a Novozymes, líder mundial na producão de enzimas industriais. }\end{array}$ \\
\hline 2011 & RA & $\begin{array}{l}\text { Investimentos e gastos em proteção ambiental foram de R\$298.514.136,00. } \\
\text { Investimentos de R } \$ 151 \text { milhões em SSMA. } \\
\text { Destinou R\$ 4,5 milhões ao PDIS. } \\
\text { Programa de Educação Ambiental Lagoa Viva que trabalha com conceitos de educação ambiental } \\
\text { e sustentabilidade ganhou } 32 \text { oficinas de temáticas variadas, capacitou cerca de mil professores } \\
\text { e beneficiou mais de } 200 \text { mil alunos de escolas públicas de Alagoas. }\end{array}$ \\
\hline 2011 & $\overline{\mathrm{DEP}}$ & Investimentos de R\$ 151 milhôes em SSMA. \\
\hline 2012 & RA & $\begin{array}{l}\text { Investimentos e gastos de R } \$ 273.246 .000,00 \text { em proteção ambiental. } \\
\text { Investimento de R } \$ 173 \text { milhões em Produtividade e SSMA. } \\
\text { O Programa de Educação Ambiental Lagoa Viva beneficiou mais de mil pessoas diretamente. } \\
\text { O Projeto Fábrica de Florestas produziu mais de } 170 \text { mil mudas, provocando a expansão do } \\
\text { projeto e culminando na inauguração de um viveiro no Jardim Botânico de Paulínia (SP), que } \\
\text { produziu cerca de } 10 \text { mil mudas. }\end{array}$ \\
\hline 2012 & DFP & $\begin{array}{l}\text { ogramação de Educação Ambiental Lagoa Viva atua em } 39 \text { municípios de Alagoa } \\
\text { ovendo oficinas voltadas à educação ambiental e capacitação para apoiar a geração de rend } \\
\text { pulacão local. }\end{array}$ \\
\hline
\end{tabular}




\begin{tabular}{|c|c|c|}
\hline 2013 & RA & $\begin{array}{l}\text { Investimento de R } \$ 26,8 \text { milhões em } 61 \text { projetos voltados para o meio ambiente. } \\
\text { Investimentos e gastos em proteção ambiental foram de R } \$ 365.373 .000,00 \text {. } \\
\text { Projeto Fábrica de Florestas resultou em uma produção de aproximadamente } 100 \text { mil mudas em } \\
\text { 2013, mais de } 10 \text { mil pessoas participaram de ações de educação ambiental e } 517 \text { pessoas foram } \\
\text { capacitadas. }\end{array}$ \\
\hline 2013 & DFP & $\begin{array}{l}\text { Investimento em pesquisas de matérias-primas químicas renováveis para o desenvolvimento do } \\
\text { butadieno verde em parceria com a Genomatica. } \\
\text { Investimento de aproximadamente } \mathrm{R} \$ 14 \text { milhões em um conjunto de programas com foco } \\
\text { na educação ambiental, inclusão social e promoção cultural das comunidades onde mantém } \\
\text { operações. } \\
\text { Expansão do projeto Fábrica de Florestas para além do litoral norte da Bahia, chegando às regiões } \\
\text { de São Paulo (SP) e Rio de Janeiro }(\mathrm{RJ}) \text {, instalando novos viveiros de mudas. }\end{array}$ \\
\hline 2014 & RA & $\begin{array}{l}\text { Investimentos de R } \$ 101.823 \text { milhões em SSMA em projetos da Unidade Petroquímicos Básicos } \\
\text { (UNIB). } \\
\text { Investimento no desenvolvimento de tecnologia voltada à produção do isopreno de fonte } \\
\text { renovável em acordo de cooperação tecnológica com a empresa norte-americana Amyris e a } \\
\text { francesa Michelin. } \\
\text { Projeto piloto para implantar em sua metodologia de decisões em investimentos um custo virtual } \\
\text { para o carbono. } \\
\text { Investimento de } \mathrm{R} \$ 27 \text { milhões em } 63 \text { projetos voltados para o meio ambiente. } \\
\text { Investimento de } \mathrm{R} \$ 224 \text { milhões em } 535 \text { projetos de SSMA. } \\
\text { Investimento de } \mathrm{R} \$ 27 \text { milhões em projetos de melhorias ambientais, além de quase } \mathrm{R} \$ 60 \\
\text { milhões em projetos de redução de gases de efeito estufa }(\mathrm{GEE}) \text {. } \\
\text { Investimentos e gastos em proteção ambiental foram de R } \$ 346.400 .000,00 \text {. } \\
\text { Em } 2014 \text {, o Projeto Somos Todos Porto Alegre teve onze Unidades de Triagem reestruturadas e } \\
\text { recebeu mais de R } \$ 350 \text { mil para melhorias emergenciais, e uma outra foi construída para receber } \\
\text { um novo grupo, formado apenas por ex-catadores. } \\
\text { O Instituto Fábrica de Florestas produziu mais de } 165 \text { mil mudas, e destas, } 83 \text { mil alcançaram o } \\
\text { estágio ideal para o plantio, tendo sido plantadas e monitoradas. }\end{array}$ \\
\hline 2014 & DFP & $\begin{array}{l}\text { O Instituto Fábrica de Florestas capacitou } 883 \text { pessoas e sensibilizou } 17 \text { mil através do Programa } \\
\text { de Educação Ambiental (PEA). Além disso, o Instituto atingiu equilíbrio nas suas atividades de } \\
\text { produção e plantio na Bahia, onde foi inaugurada a } 3^{\text {a }} \text { Estação Ambiental Braskem construída } \\
\text { com soluções em plástico, dedicada à promoção da educação ambiental. } \\
\text { Investimentos de cerca de R\$ } 18 \text { milhões em projetos socioambientais e culturais, de abrangência } \\
\text { nacional e internacional, destacando-se os Projetos Ser + Realizador e Edukatu. }\end{array}$ \\
\hline 2015 & RA & $\begin{array}{l}\text { Investimento de R\$ } 31 \text { milhões em projetos de melhorias ambientais. } \\
\text { Investimentos R } \$ 1,2 \text { milhão na melhoria de torres de resfriamento, medição, purgadores e } \\
\text { eliminação de perdas físicas no período de } 2013 \text { a } 2015 \text { na PVC2 AL que propiciaram a redução } \\
\text { de } 23 \% \text { na vazão média de captação de água do rio dos Remédios, } 19 \% \text { de melhoria do índice de } \\
\text { consumo de água e } 14 \% \text { de redução do índice de geração de efluentes líquidos, totalizando um } \\
\text { ganho estimado da ordem de R\$ } 700.000 / \text { ano. } \\
\text { Investimento de R } \$ 28.000 \text { em projeto de recuperação de água de resfriamento dos analisadores } \\
\text { dos fornos de pirolise de olefinas na UNIB } 3 \text { ABC que permitiram uma redução de } 0,014 \mathrm{~m}^{3} / \mathrm{t} \text { no } \\
\text { indice de efluente, representando uma economia estimada de R } \$ 150.000 / \text { ano. } \\
\text { Investimentos e gastos em proteção ambiental foram de } \mathrm{R} \$ 602.800 .000,00 \\
\text { Investimentos, no Brasil, de R } \$ 25,8 \text { milhões em projetos socioambientais, culturais e esportivos. } \\
\text { Cerca de R\$ } 100 \text { mil foram investidos no projeto de reciclagem por meio do PICPlast. } \\
\text { Investimento de R } \$ 114,43 \text { milhões em SSMA. } \\
\text { O Instituto Fábrica de Florestas contribuiu para a construção de comunidades ambientalmente } \\
\text { responsáveis a partir da ampliação, recuperação e manutenção de áreas verdes, com educação } \\
\text { ambiental integrada. Capacitou mais de mil pessoas e sensibilizou } 16.739 \text { mil. Além disso, mais } \\
\text { de } 116 \text { mil mudas foram produzidas e, destas, cerca de } 39 \text { mil plantadas e monitoradas. }\end{array}$ \\
\hline 2015 & DFP & $\begin{array}{l}\text { Investimento social, no Brasil, de } \mathrm{R} \$ 24,4 \text { milhões em projetos socioambientais e culturais. } \\
\text { O Instituto Fábrica de Florestas atingiu a expressiva marca de } 1 \text { milhão de mudas produzidas e } \\
\text { mais de } 600 \text { mil plantadas em seus sete anos de atuação. }\end{array}$ \\
\hline
\end{tabular}




\begin{tabular}{|c|c|c|}
\hline 2016 & $\begin{array}{c}\text { RA } \\
\text { DFP }\end{array}$ & $\begin{array}{l}\text { Investimento social, no Brasil, de cerca de R } \$ 26 \text { milhões em projetos socioambientais e culturais. } \\
\text { Nos Estados Unidos e na Alemanha, a Braskem investiu mais de R } \$ 550 \text { mil e no México, R } \$ \\
1,3 \text { milhão. } \\
\text { Investimentos, no Brasil, de R } \$ 27,5 \text { milhões em projetos socioambientais, culturais e esportivos. } \\
\text { O Projeto Ser+ Realizador beneficiou mais de } 3.400 \text { catadores e, dentre as cooperativas apoiadas, } \\
47 \text { receberam assessoria técnica e garantiram o envio de mais de } 30 \text { mil toneladas de resíduos } \\
\text { para a reciclagem. } \\
\text { O Edukatu atingiu a marca de } 28 \text { mil participantes, sendo cerca de } 2.400 \text { em cidades em que a } \\
\text { Braskem opera. Mais de } 10 \text { mil alunos se envolveram diretamente em projetos de intervenção em } \\
\text { suas Comunidades escolares, sensibilizando } 63 \text { mil pessoas para o consumo consciente. } \\
\text { Investimento de R } \$ 103,9 \text { milhões em SSMA. } \\
\text { O Instituto Fábrica de Florestas capacitou mais de } 1.036 \text { pessoas e sensibilizou } 27.506 \text { mil. } \\
\text { Além disso, mais de } 88.407 \text { mil mudas foram produzidas e, destas, cerca de } 46.628 \text { mil plantadas } \\
\text { e monitoradas. } \\
\text { Investimento de R } \$ 2,7 \text { milhões em um novo sistema de controle que gera uma economia de } \\
\text { aproximadamente } 10 \mathrm{MW} \text { de energia diariamente. } \\
\text { Investimentos e gastos em protecão ambiental foram de } \mathrm{R} \$ 507.400 .000 .00\end{array}$ \\
\hline
\end{tabular}

Fonte: Dados da pesquisa (2018).

A evidenciação de investimentos realizada pela Brasken S.A. em seus documentos é tanto quantitativa como qualitativa, uma vez que em muitas das sentenças apresentadas é possível observar valores monetários e não monetários, seguidos de uma descrição referente a esses números. Foram evidenciados, segundo a classificação de Rover, Borba e Borget (2008), investimentos em educação ambiental, investimentos para manutenção dos processos operacionais e melhoria do meio ambiente, investimento com projetos ou programas ambientais e investimentos para preservação e proteção ambiental.

\subsubsection{Elekeiroz S.A.}

Os Quadros 6 e 7 referem-se a evidenciação de custos e investimentos ambientais da empresa Elekeiroz S.A. nas DFP e no RS durante os anos de 2010 a 2016.

Quadro 6 - Evidenciação de custos ambientais na empresa Elekeiroz S.A.

\begin{tabular}{|c|l|l|}
\hline Exercício & Relatório & \\
\hline 2010 & RS & Gastos de R\$ 9.298.590,00 em proteção ambiental. \\
\hline 2010 & DFP & Não houve evidenciação. \\
\hline 2011 a 2016 & $\begin{array}{l}\text { DFP } \\
\text { RS }\end{array}$ & Não houve evidenciação. \\
\hline
\end{tabular}

Fonte: Dados da pesquisa (2018).

Durante os sete exercícios analisados foi identificada apenas uma sentença referente a evidenciação de custos ambientais, sendo esta sentença classificada, de acordo com Hansen e Mowen (2003) como custos de prevenção ambiental. A sentença, segundo Rover, Borba e Borgert (2008) é do tipo quantitativa monetária.

No próximo quadro são apresentadas as informações referentes a investimentos ambientais evidenciadas pela empresa. 
Quadro 7 - Evidenciação de investimentos ambientais na empresa Elekeiroz S.A.

\begin{tabular}{|c|c|c|}
\hline Exercício & Relatório & Descrição da informação \\
\hline 2010 & $\begin{array}{c}\text { DFP } \\
\text { RS }\end{array}$ & $\begin{array}{l}\text { Lançamento de uma linha completa de Resinas Sustentáveis. } \\
\text { Investimento de R\$ } 14,9 \text { milhões em programas de produtividade, manutenção das instalações } \\
\text { existentes, segurança dos colaboradores e preservação do meio ambiente. } \\
\text { Implantação de projetos e sistemas que reduziram o consumo de água pela empresa e a emissão } \\
\text { de gás carbônico para o meio ambiente. } \\
\text { Investimento em proteção ambiental de R } \$ 1.624 .000,00 \text { no projeto de Coleta de CO2. } \\
\text { Destinou R } \$ 153 \text { mil, por meio da Lei Rouanet de Incentivo à Cultura, a projetos e programas } \\
\text { que associam cultura, saúde e educação formal à proteção ambiental ao público de crianças e } \\
\text { adolescentes entre eles o projeto Planeta Água - Mata Atlântica e Paisagens voltado a educação } \\
\text { ambiental. }\end{array}$ \\
\hline 2011 & $\overline{\mathrm{DFP}}$ & $\begin{array}{l}\text { Investimento no desenvolvimento do Plastek } 81 \text { plastificante formulado a partir de matéria- } \\
\text { prima renovável. } \\
\text { Investimento de R } \$ 63,5 \text { milhões em programas de produtividade, manutenção das instalações } \\
\text { existentes. seguranca dos colaboradores e preservacão do meio ambiente. }\end{array}$ \\
\hline 2011 & $\mathrm{RS}$ & $\begin{array}{l}\text { Investimento de R } \$ 9.409 .000,00 \text { em meio ambiente. } \\
\text { Manutenção da operação para redução da emissão de gás carbônico, o que causou uma redução } \\
\text { de } 5.000 \text { toneladas. }\end{array}$ \\
\hline 2012 & $\begin{array}{c}\text { DFP } \\
\text { RS }\end{array}$ & $\begin{array}{l}\text { Investimento de } \mathrm{R} \$ 20,9 \text { milhões em programas de produtividade, segurança e preservação do } \\
\text { meio ambiente. } \\
\text { Investimento de } \mathrm{R} \$ 17,5 \text { milhões para a ampliação da capacidade de produção da resina de } \\
\text { poliéster insaturado. } \\
\text { Investimento de } \mathrm{R} \$ 10.573 .000,00 \text { em meio ambiente. } \\
\text { Manutenção de projetos de reúso de água que minimizaram a emissão de efluentes em até } 16,8 \\
\text { mil metros cúbicos. }\end{array}$ \\
\hline 2013 & RS & Investimento de R\$ $10.116 .000,00$ em meio ambiente. \\
\hline 2014 & RS & $\begin{array}{l}\text { Aproveitamento do calor gerado nos processos produtivos para gerar } 70 \% \text { da energia elétrica } \\
\text { consumida no site da Várzea Paulista (SP). } \\
\text { Patrocínio ao projeto Ler Ibama que através desenvolvimento do gibi Vida Livre teve como } \\
\text { propósito despertar nas criancas a consciência ambiental. }\end{array}$ \\
\hline 2015 & $\mathrm{RS}$ & $\begin{array}{l}\text { Investimentos de R } \$ 2,8 \text { milhôes nas unidades de produção, aumentando a competitividade nas } \\
\text { cadeias produtivas e tornando as operações mais sustentáveis. } \\
\text { Patrocínio à Cartilha Ambiental do município de Várzea Paulista, em parceria com o IBAMA. }\end{array}$ \\
\hline 2013 a 2015 & DFP & e evidenciação. \\
\hline 2016 & $\mathrm{RS}$ & ão. \\
\hline
\end{tabular}

Fonte: Dados da pesquisa (2018).

Os investimentos ambientais evidenciados pela empresa são classificados, de acordo com Rover, Borba e Borgert (2008), como investimentos em projetos ou programas ambientais, investimentos para manutenção dos processos operacionais e melhoria do meio ambiente, investimentos em educação ambiental e investimentos para preservação e proteção ambiental. As sentenças são do tipo declarativa, quantitativa monetária e quantitativa não monetária, segundo os autores acima.

\subsubsection{Cristal Pigmentos do Brasil S.A.}

Os Quadro 8 e 9 apresentam as informações relacionadas a custos e investimentos ambientais evidenciadas na DFP da Cristal Pigmentos S.A. a partir do exercício de 2013 até o exercício de 2016. 
Quadro 8 - Evidenciação de custos ambientais na empresa Cristal Pigmentos S.A.

\begin{tabular}{|c|c|c|}
\hline Exercício & Relatório & Descrição da informação \\
\hline 2013 & DFP & $\begin{array}{l}\text { Provisão de R\$ } 34.818 \text { para recuperação e reflorestamento da área da mina. } \\
\text { Provisão de } \mathrm{R} \$ 1.253 \text { referente a desembolsos relacionados aos custos de operação e manutenção } \\
\text { de equipamentos constituintes do sistema de remediação ambiental. }\end{array}$ \\
\hline 2014 & DFP & $\begin{array}{l}\text { Provisão de R } \$ 893 \text { referente a desembolsos relacionados aos custos de operação e manutenção } \\
\text { de equipamentos constituintes do sistema de remediação ambiental. } \\
\text { Provisão de } \$ \text { Q } \$ 9.928 \text { para remediação ambiental. }\end{array}$ \\
\hline 2015 & DFP & $\begin{array}{l}\text { Provisão de R\$331 referente a desembolsos relacionados aos custos de operação e manutenção } \\
\text { de equipamentos constituintes do sistema de remediação ambiental. } \\
\text { Provisão de } R \$ 15292 \text { nara remediacão ambiental }\end{array}$ \\
\hline 2016 & DFP & $\begin{array}{l}\text { Provisão de R\$ } 1.893 \text { referente a desembolsos relacionados aos custos de operação e manutenção } \\
\text { de equipamentos constituintes do sistema de remediação ambiental. } \\
\text { Provisão de R\$ } 5.667 \text { para remediação ambiental. }\end{array}$ \\
\hline
\end{tabular}

Fonte: Dados da pesquisa (2018).

De acordo com Tinoco e Kraemer (2011) os custos ambientais evidenciados pela empresa em suas DFP no período estudado são custos com contingência e custos convencionais. Além disso, são do tipo quantitativa monetário, segundo Rover, Borba e Borgert (2008). Acrescenta-se que só foram encontradas DFP no website da empresa a partir do exercício de 2013.

O Quadro 9 apresenta as informações relacionadas aos investimentos ambientais evidenciados pela Cristal Pigmentos S.A.

Quadro 9- Evidenciação de investimentos ambientais na empresa Cristal Pigmentos S.A.

\begin{tabular}{|c|c|l|}
\hline Exercício & Relatório & \multicolumn{1}{|c|}{ Descricão da informação } \\
\hline 2013 & DFP & $\begin{array}{l}\text { Investimento de R\$ } 15.966 \text { mil concentrados na Bahia nás áreas de meio ambiente, segurança, } \\
\text { confiabilidade, automação e eficiência do processo. } \\
\text { Programa de Educação Ambiental realizado na Paraíba na base de Pesquisas Ambientais da mina. } \\
\text { Plantio de } 77.556 \text { mudas através do Programa de de Recomposição de Áreas Mineradas. }\end{array}$ \\
\hline 2014 & DFP & $\begin{array}{l}\text { Investimento de R\$ 25.018 mil concentrados na Bahia nas areas de meio ambiente, segurança, } \\
\text { confiabilidade, automação e eficiência do processo. } \\
\text { Programa de Educação Ambiental realizado na base de Pesquisas Ambientais da mina. } \\
\text { Plantio de 68.796 mudas através do Programa de de Recomposição de Áreas Mineradas. }\end{array}$ \\
\hline 2015 & DFP & $\begin{array}{l}\text { Investimento de R\$ 23.285 mil concentrados na Bahia nas areas de meio ambiente, segurança, } \\
\text { confiabilidade, automação e eficiência do processo. } \\
\text { Programa de Educação Ambiental realizado na base de Pesquisas Ambientais da mina. }\end{array}$ \\
\hline 2016 & DFP & Não houve evidenciação. \\
\hline
\end{tabular}

Fonte: Dados da pesquisa (2018).

Os investimentos evidenciados por essa empresa, segundo Rover, Borba e Borgert (2008), são classificados em: investimentos em educação ambiental; investimentos com projetos ou programas ambientais; e investimentos para preservação e proteção ambiental. Além disso, são sentenças do tipo descritiva, quantitativa monetária e quantitativa não-monetária, conforme esses mesmos autores.

\subsubsection{Unipar Carbocloro S.A.}

No Quadro 10 são evidenciadas as informações referentes aos custos ambientais incorridos pela Unipar Carbocloro S.A. constantes nas Demonstrações Financeiras Padronizadas (DFP) durante os exercícios de 2010 a 2016. 
Quadro 10 - Evidenciação de custos ambientais na empresa Unipar Carbocloro S.A.

\begin{tabular}{|c|c|l|}
\hline Exercício & Relatório & \multicolumn{1}{|c|}{ Descrição da informação } \\
\hline 2010 & DFP & Provisão de R\$ 545 mil para remediação ambiental. \\
\hline 2011 & DFP & Provisão de R\$ 434 mil para remediação ambiental. \\
\hline 2012 & DFP & Provisão de R\$ 426 mil para remediação ambiental. \\
\hline 2013 & DFP & Não houve evidenciação \\
\hline 2014 & DFP & Reversão contingência ambiental no valor de R\$ 664 mil. \\
\hline 2015 a 2016 & DFP & Não houve evidenciação \\
\hline
\end{tabular}

Fonte: Dados da pesquisa (2018).

As informações sobre custos ambientais evidenciadas pela empresa Unipar Carbocloro S.A. são quantitativas monetárias, segundo Rover, Borba e Borgert (2008), sendo formadas apenas por provisões ambientais e reversão de contingência sem que nenhum detalhe relacionado a essas informações fosse explicitado. De acordo com Tinoco e Kraemer (2011), esses custos podem ser classificados em custos com contingências. Salienta-se que não foram evidenciadas informações referentes a investimentos ambientais no período analisado.

\subsection{EVIDENCIAÇÃO DE CUSTOS AMBIENTAIS}

A Tabela 1 apresenta de forma sintetizada a quantidade de sentenças relacionadas a custos ambientais evidenciadas pelas empresas da amostra no período analisado a partir dos relatórios consultados.

Tabela 1 - Evidenciação de custos ambientais

\begin{tabular}{l|c|c|c|c|c|c|c}
\hline $\begin{array}{l}\text { Evidenciações de custos } \\
\text { ambientais }\end{array}$ & $\mathbf{2 0 1 0}$ & $\mathbf{2 0 1 1}$ & $\mathbf{2 0 1 2}$ & $\mathbf{2 0 1 3}$ & $\mathbf{2 0 1 4}$ & $\mathbf{2 0 1 5}$ & $\mathbf{2 0 1 6}$ \\
\hline Fertilizantes IIeringer S.A. & 0 & 1 & 2 & 2 & 0 & 1 & 1 \\
Brasken S.A. & 6 & 2 & 2 & 2 & 3 & 2 & 3 \\
Elekeiroz S.A. & 1 & 0 & 0 & 0 & 0 & 0 & 0 \\
Cristal Pigmentos S.A. & - & - & - & 2 & 2 & 2 & 2 \\
Unipar Carbocloro S.A. & 1 & 1 & 1 & 0 & 1 & 0 & 0 \\
\hline
\end{tabular}

Fonte: Dados da pesquisa (2018).

Os dados encontrados foram classificados em categorias de custos ambientais segundo as classificações apresentadas por Tinoco e Kraemer (2011), Rover, Borba e Borgert (2008) e Hansen e Mowen (2003). A Tabela 2 apresenta uma síntese dessas classificações a partir das informações evidenciadas pelas empresas da amostra.

Tabela 2 - Categorias de custos ambientais

\begin{tabular}{lc}
\hline Categorias de custos ambientais & Total \\
\hline Custos com contingências & 4 \\
Custos de detecção ambiental & 1 \\
Custos de prevenção ambiental & 2 \\
Custos convencionais & 1 \\
Total & $\mathbf{8}$ \\
\hline
\end{tabular}

Fonte: Dados da pesquisa (2018). 
Nota-se que a categoria de custos ambientais mais evidenciada foi a de custos com contingência, seguida dos custos de prevenção ambiental. Os custos com detecção ambiental e os custos apareceram uma vez cada.

\subsection{EVIDENCIAÇÃO DE INVESTIMENTOS AMBIENTAIS}

A Tabela 3 apresenta de forma sintetizada a quantidade de sentenças relacionadas a investimentos ambientais evidenciadas pelas empresas da amostra no período analisado a partir dos relatórios consultados.

Tabela 3 - Evidenciação de investimentos ambientais

\begin{tabular}{l|c|c|c|c|c|c|c}
\hline Evidenciações de custos ambientais & $\mathbf{2 0 1 0}$ & $\mathbf{2 0 1 1}$ & $\mathbf{2 0 1 2}$ & $\mathbf{2 0 1 3}$ & $\mathbf{2 0 1 4}$ & $\mathbf{2 0 1 5}$ & $\mathbf{2 0 1 6}$ \\
\hline Fertilizantes Heringer S.A. & 1 & 6 & 5 & 2 & 1 & 6 & 2 \\
Brasken S.A. & 15 & 6 & 6 & 6 & 11 & 9 & 8 \\
Elekeiroz S.A. & 5 & 4 & 4 & 1 & 2 & 2 & 0 \\
Cristal Pigmentos S.A. & - & - & - & 3 & 3 & 2 & 0 \\
Unipar Carbocloro S.A. & 0 & 0 & 0 & 0 & 0 & 0 & 0 \\
\hline
\end{tabular}

Fonte: Dados da pesquisa (2018).

Os dados encontrados foram classificados em categorias de investimentos ambientais conforme as categorias apresentadas na Tabela 4.

Tabela 4 - Categorias de investimentos ambientais

\begin{tabular}{lc}
\hline Categorias de investimentos ambientais & Total \\
\hline Investimentos para manutenção dos processos operacionais e melhorias do meio ambiente & 3 \\
Investimentos com educação ambiental & 2 \\
Investimentos com projetos ou programas ambientais & 4 \\
Investimentos para proteção e preservação ambiental & 4 \\
Total & $\mathbf{1 3}$ \\
\hline
\end{tabular}

Fonte: Dados da pesquisa (2018).

Foram encontradas 13 categorias de investimentos no período analisado, sendo que as categorias mais evidenciadas foram os investimentos com projetos ou programas ambientais e investimentos para proteção e preservação ambiental.

As 39 sentenças referente a custos ambientais identificadas incluem, por exemplo, provisões para contingências e custos com prevenção e gestão ambiental. Já as sentenças relacionadas aos investimentos totalizaram 111 e incluem, por exemplo, evidenciações referentes a investimentos em educação ambiental e projetos de proteção ambiental.

Os dados indicam que o tipo de evidenciação mais adotado pelas empresas para apresentar os seus custos e investimentos ambientais foi a quantitativa monetária, seguida da declarativa e da quantitativa não-monetária, respectivamente. Salienta-se que não foram encontradas sentenças quantitativas monetária e não-monetária.

O documento mais utilizado para evidenciar as informações sobre custos e investimentos ambientais foram as Demonstrações Financeiras Padronizadas. Essas informações evidenciadas 
relacionadas tanto a custos quanto a investimentos ambientais foram predominantemente quantitativas, embora algumas empresas tenham apresentando breves descrições qualitativas sobre os seus custos e investimentos, de modo que esses achados corroboram com (ASSUNÇÃO, 2017; ROVER; BORBA; BORGERT, 2008).

\section{CONCLUSÃO}

O objetivo da pesquisa foi investigar a evidenciação dos custos e investimentos ambientais das empresas pertencentes ao setor de químicos listadas na B3.

Quanto aos custos ambientais, observou-se que foram evidenciadas, predominantemente, sentenças relacionadas a categoria custos com contingência, de acordo com a classificação de Tinoco e Kraemer (2011), que está relacionada a multas e penalidades que podem afetar as empresas. Outra categoria que obteve destaque foi a de custos de prevenção ambiental, que visa prevenir o impacto das atividades desenvolvidas pelas empresas no meio ambiente.

No que diz respeito à evidenciação de investimentos ambientais destacaram-se as categorias: investimentos com projetos ou programas ambientais, que englobam investimentos diretos em projetos ou programas destinados a contribuir para uma melhor prática ambiental interna e externa à empresa e investimentos para proteção e preservação ambiental que visam mitigar os efeitos da atuação da empresa no meio ambiente. Salienta-se que a maioria das informações sobre custos e investimentos ambientais divulgadas foram do tipo quantitativa monetária, seguida das evidenciações do tipo descritiva e quantitativa não-monetária.

Destaca-se que apesar das muitas sentenças encontradas estarem na forma quantitativa, estas também foram acompanhadas de explicações do que esses números representam. Indicando que a empresas estão buscando se legitimar perante a sociedade sobre questões ambientais dando uma maior qualidade a evidenciação dessas informações.

Também foi possível observar que não houve uma homogeneidade no nível de evidenciação entre as empresas estudadas, de modo que algumas empresas evidenciaram muitas informações relacionadas a custos e investimentos em meio ambiente, enquanto outras, como foi o caso da Unipar Carbocloro S.A. preocuparam-se em evidenciar apenas aspectos relacionados aos seus custos ambientais.

Ademais, os documentos utilizados pelas empresas da amostra para evidenciar as informações também não foram homogêneos. Algumas empresas utilizaram os Formulários 20F, Relatório Anual e Relatório de Sustentabilidade, enquanto outras utilizaram apenas as Demonstrações Financeiras Padronizadas.

Foi observado também que de um modo geral as empresas estão evidenciando poucas informações de cunho ambiental relacionados a custos e investimentos em meio ambiente, soma-se a isso a falta de padronização das informações encontradas, o que dificulta a comparabilidade dessas informações entre as empresas.

A pesquisa encontrou limitação na quantidade de informações evidenciadas, especialmente devido ao fato de algumas empresas não divulgarem informações ambientais nos documentos por elas elaborados e que estavam disponíveis nos websites. 
Para futuras pesquisas recomenda-se estudos comparativos entre os diversos setores envolvendo tantas empresas brasileiras quanto estrangeiras de modo a identificar nos relatórios semelhanças e diferenças entre as informações evidenciadas, além de analisar qualitativamente essas informações fornecidas pelas empresas sob a perspectiva da Teoria da Legitimidade, contribuindo, assim, para a ampliação dos estudos sobre evidenciação ambienta

\section{REFERÊNCIAS}

ALMEIDA-SANTOS, P. S.; VARGAS, A. J.; ALMEIDA, D. M.; LAVARDA, C. E. F. Nível de disclosure verde e a reputação corporativa ambiental das companhias brasileiras de capital aberto.

Revista Contemporânea de Contabilidade, v. 9, n. 18, p. 63-82, jul./dez. 2012.

\section{ASSOCIAÇÃO BRASILEIRA DA INDÚSTRIA QUÍMICA. Desempenho da Indústria Química}

Brasileira. 2015. Disponível em: <http://www.abiquim.org.br/pdf/livreto-de-dados-2015-paginas. pdf>. Acesso em: 11 mai. 2018.

BARDIN, L. Análise de conteúdo. Lisboa: Edições 70, 1977.

BRASIL. Lei ${ }^{\circ}$ 10.165, de 27 de dezembro de 2000. Altera a Lei ${ }^{\circ}$ 6.938, de 31 de agosto de 1981, que dispõe sobre a Política Nacional do Meio Ambiente, seus fins e mecanismos de formulação e aplicação, e dá outras providências. Diário Oficial da União, Poder Executivo, Brasília, DF, 28 dez. 2000. Disponível em: <http://www.planalto.gov.br/ccivil_03/Leis/.gov.br/ccivil_03/Leis/ L10165.htm>. Acesso em: 13 mar. 2018.

BRASIL. Lei n 12.305 , de 02 de agosto de 2010. Institui a Política Nacional de Resíduos Sólidos; altera a Lei $\mathrm{n}^{\circ}$ 9.605, de 12 de fevereiro de 1998; e dá outras providências. Diário Oficial da União, Poder Executivo, Brasília, DF, 03 ago. 2010. Disponível em: <http://www.planalto.gov.br/ ccivil_03/_ato2007-2010/2010/lei/112305.htm>. Acesso em: 11 mai. 2018.

CERVO, A. L.; BERVIAN, P. A.; SILVA, Roberto. Metodologia científica. 6. ed., 6. reimpressão. São Paulo: Pearson Prentice Hall, 2010.

COMIER, D.; MAGNAN, M. The economic relevance of environmental disclosure and its impact on corporate legitimacy: An empirical investigation. Business Strategy and the Environment, 2013.

CONCEIÇÃO, S. H.; DOURADO, G. B.; BAQUEIRO, A. G.; FREIRE, S.; BRITO, P. C. Fatores determinantes no disclosure em Responsabilidade Social Corporativa (RSC): Um estudo qualitativo e quantitativo com empresas listadas na Bovespa. Gestão de Produção, v. 18, n. 3, p. 461-472, 2011.

CORREA, J. C.; GONÇALVES, M. N.; MORAES, R. O. Disclosure ambiental das companhias do setor de petróleo, gás e biocombustíveis listadas na BM\&FBovespa: uma análise à luz da Teoria da Legitimidade. Revista de Gestão Ambiental e Sustentabilidade, v. 4, n. 3, set./dez. 2015. 
DEEGAN, C. The legitimizing effect of social and environmental disclosures - a theorical foundation. AAAJ - Accounting, Auditing \& Accountability Journal, v. 15, n. 3, p. 282-311, 2002.

FONSECA, D.; MACHADO, D. G.; COSTA, A. A.; SOUZA, M. A. Evolução da evidenciação de custos ambientais: um estudo em empresas do setor de papel e celulose - integrantes do índice de sustentabilidade empresarial - ISE. In: CONGRESSO BRASILEIRO DE CUSTOS, 22., 2015, Foz do Iguaçu. Anais... Foz do Iguaçu, 2015.

GIL, A. C. Métodos e técnicas de pesquisa social. 6. ed. São Paulo: Atlas, 2008.

HANSEN, Don R.; MOWEN, M. M. Gestão de custos: contabilidade e controle. São Paulo: Pioneira Thomson Learning, 2003.

MACEDO, M. A. S.; SOUSA, A. C.; SOUSA, A. C. C.; CÍPOLA, F. C. Desempenho de empresas socialmente responsáveis: uma análise por índices contábil-financeiros. In: CONGRESSO BRASILEIRO DE CUSTOS, 14., 2007, João Pessoa. Anais... João Pessoa, 2007.

MARQUEZAN, L. H. F.; SEIBERT, R. M.; BARTZ, D.; BARBOSA, M. A.G.; ALVES, T. W. Análise dos determinantes do disclosure verde em relatórios anuais de empresas listadas na BM\&FBOVESPA. Contabilidade, Gestão e Governança, Brasília, v. 18, n. 1, p. 127-150, jan./abr. 2015.

MARTINS, E. Contabilidade de Custos. 10. ed. São Paulo: Atlas, 2010.

MARTINS, G. A.; THEÓPHILO, C. R. Metodologia da investigação científica para ciências sociais aplicadas. 1. ed. São Paulo: Atlas, 2007.

MORAES, M. A.; THEIS, V.; VIER, M. B.; SCHREIBER, D. Análise dos custos ambientais relacionados com a gestão de resíduos em indústrias químicas. Revista de Administração Contabilidade e Economia, v. 16, n. 2, p. 505-522, mai./ago. 2017.

NOSSA, V. Disclosure ambiental: uma análise do conteúdo dos relatórios ambientais do setor de papel e celulose em nível internacional. 2002. 246 f. Tese (Doutorado em Contabilidade e Controladoria) - Faculdade de Economia, Administração e Contabilidade, Universidade de São Paulo, São Paulo, 2002.

PARENTE, P. H. N.; MOTA, A. F.; CABRAL, A. C. A; SANTOS, S. M. Teoria Institucional e disclosure de sustentabilidade: uma investigação no setor de energia elétrica. Revista de Administração, Contabilidade e Economia, Joaçaba, v. 13, n. 3, set./dez. 2014.

PATTEN, D.; CHO, C. The role of environmental disclosures as tools of legitimacy: a research note. AOS - Accounting, Organizations and Society, v. 32, n. 7, p. 639-647, 2007.

RAFAELLI, S. C. D.; AMARO, H. D.; SILVA, W. V.; ALMEIDA, L. B. Alisamento de resultados e disclosure ambiental: uma investigação no setor de siderurgia e metalurgia brasileiro. Revista Ambiente Contábil, v. 6, n.1, p. 163-182, jan./jun. 2014. 
RIBEIRO, M. S. Contabilidade ambiental. 2. ed. São Paulo: Saraiva, 2010.

RODRIGUES, J. M.; MACHADO, D. G.; CRUZ, A. P. C. Evidenciação de custos ambientais em empresas do segmento de adubos e fertilizantes. Revista Contemporânea de Contabilidade, v. 8, n. 15 , p. 63-86, jan./jun. 2011.

ROVER, S.; BORBA, J. A.; BORGERT, A. Como as empresas classificadas no índice de sustentabilidade empresarial (ISE) evidenciam os custos e investimentos ambientais? Revista de Custos e @gronegócio online, v. 4, n. 1, jan./abr. 2008.

SILVA, J. O.; CUNHA, P. R.; KLANN, R. C.; SCARPIN, J. E. Evidenciação dos custos ambientais nas empresas que compõem o índice de sustentabilidade empresarial (ISE). Revista Contemporânea de Contabilidade, v. 7, n. 14, p. 159-182, jul./dez. 2010.

SILVA, L. M.; SILVA, R. P. A.; ALVES, I. J. B. R.; OLIVEIRA, K. P. S. Análise dos investimentos em responsabilidade socioambiental das empresas do índice de sustentabilidade empresarial listadas na BM\&FBovespa. In: CONGRESSO BRASILEIRO DE CUSTOS, 21., 2017, Anais... Florianópolis, 2017.

SILVA, M. N.; LIMA, J. A. S. O.; FREITAS, M. A. L.; SILVA FILHO, L. L.; LAGIOIA, U. C. T. Determinantes do disclosure ambiental nos relatórios de empresas listadas na BM\&FBovespa. In: CONGRESSO USP CONTROLADORIA E CONTABILIDADE, 14., 2014, Anais... São Paulo, 2014.

SPENCE, C.; HUSILLOS, J.; CORREA-RUIZ, C. Cargo cult science and the death of politics: A critical review of social and environmental accounting research, Critical Perspectives on Accounting, 21, 76-89. 2010.

SUCHMAN, M. C. Managing Legitimacy: strategic and institutional approaches. The Academy of Management Review, v. 20, n. 3, p. 571-610, 1995.

TINOCO, J. E. P.; KRAEMER, M. E. P. Contabilidade e gestão ambiental. 3. ed. São Paulo: Atlas, 2011.

VELLANI, C. L.; NAKAO, S. H. Investimentos ambientais e redução de custos. Revista de Administração da UNIMEP, v. 7, n. 2, p. 57-75, mai./ago. 2009. 